\title{
Interactive comment on "Secondary organic aerosol formation from smoldering and flaming combustion of biomass: a box model parametrization based on volatility basis set" by Giulia Stefenelli et al.
}

Giulia Stefenelli et al.

giulia.stefenelli@psi.ch

Received and published: 20 June 2019

The comment was uploaded in the form of a supplement:

https://www.atmos-chem-phys-discuss.net/acp-2018-1308/acp-2018-1308-AC2-

supplement.pdf 